\title{
Association of $2^{\prime}-5^{\prime}$ oligoribonucleotides
}

\author{
Ryszard Kierzek, Liyan $\mathrm{He}^{1}$ and Douglas H.Turner * \\ Institute of Bioorganic Chemistry, Polish Academy of Sciences, 60-704 Poznan, Noskowskiego 12/14, \\ Poland and ${ }^{1}$ Department of Chemistry, University of Rochester, Rochester, NY 14627-0216, USA
}

Received December 9, 1991; Revised and Accepted February 28, 1992

\begin{abstract}
Oligoribonucleotides with $2^{\prime}-5^{\prime}$ linkages have been synthesized on solid support. UV melting and CD experiments indicate complementary strands associate to give complexes with melting temperatures 30 to $40^{\circ} \mathrm{C}$ lower than for duplexes formed by $3^{\prime}-5^{\prime}$ oligoribonucleotides with the same sequence. UV melting and imino proton NMR spectra and NOEs for $\left(2^{\prime}-5^{\prime}\right)$ CGGCGCCG are consistent with formation of an antiparallel duplex. The results suggest greater duplex stability was one factor favoring $3^{\prime}-5^{\prime}$ over $2 '-5$ ' linkages in evolution.
\end{abstract}

\section{INTRODUCTION}

The discovery of catalytic and antisense regulatory activity has led to renewed interest in the properties of nucleic acids $(1-3)$. Almost all naturally occurring nucleic acids have $3^{\prime}-5^{\prime}$ phosphodiester linkages. This coupling dominates despite the fact that studies suggest $2^{\prime}-5^{\prime}$ linkages were easier to form in the prebiotic world (4). It has been suggested that the preference for $3^{\prime}-5^{\prime}$ is due to the slower rate of hydrolysis for $3^{\prime}-5^{\prime}$ linkages and/or the inability of $2^{\prime}-5^{\prime}$ linked nucleic acids to form helixes $(5,6)$. The effects of backbone structure on helix formation are also important for the design of antisense agents. For example, different backbones have been employed to alter the rate of degradation of oligomers by nucleases (3).

Theoretical studies have led to different predictions about the possibility of forming helixes with $2^{\prime}-5^{\prime}$ linked nucleic acids $(7,8)$. Almost all experimental studies of $2^{\prime}-5^{\prime}$ oligomers have been limited to dimers and trimers $(6,9-16)$. In this work, all D $2^{\prime}-5^{\prime}$ oligoribonucleotides of up to 10 nucleotides have been synthesized with modifications of methods previously used for synthesis of $3^{\prime}-5^{\prime}$ oligomers (17). The associations of these oligomers have been studied by UV melting, CD, and NMR. The results indicate that $2^{\prime}-5^{\prime}$ oligomers with Watson-Crick complementarity are able to form ordered structures.

\section{MATERIALS AND METHODS}

\section{Reagents and General Procedures}

Nucleosides, 4', 4' -dimethoxytrityl chloride, tert-butyldimethylsilyl chloride, and phenoxyacetyl chloride were obtained from Aldrich. Methyl N, N, N', $\mathbf{N}^{\prime}$-tetraisopropyl phosphordiamidite was synthesized by a published procedure (18). Thin layer chromatography (TLC) was performed on Merck $60 \mathrm{~F}_{254}$ silica gel plates of 0.25 or $0.50 \mathrm{~mm}$ in $1: 1 \mathrm{v} / \mathrm{v}$ ethyl acetate-hexanes (solvent A), 7:1:2 v/v/v 2-propanol-ammonia-water (solvent B), and 55:35:10 v/v/v 1-propanol-ammonia-water (solvent C). Reversed phase TLC was performed on reverse phase silica gel plates in 7:3 v/v acetone-water (solvent D). Column chromatography was performed on Merck silica gel H60.

\section{Synthesis}

5'-O-dimethoxytrityl-3'-O-tert-butyldimethylsilyl-N-protected nucleosides were prepared by a published procedure with the following modifications (19). Hexamethyldisilazane (HMDS) was first used for transient protection of hydroxyl groups. Then the amino group was protected with phenoxyacetyl for guanosine and adenosine and with acetyl for cytidine (20). Following protection of the amino groups, the intermediate protecting group, trimethylsilyl, was removed with triethylammonium fluoride $(21,22)$.

Phosphoramidites were prepared from the blocked nucleosides by first drying the appropriate blocked nucleoside $(3 \mathrm{mM})$ and tetrazole $(0.22 \mathrm{~g}, 3.15 \mathrm{mM})$ in vacuo for $3 \mathrm{~h}$, adding anhydrous acetonitrile $(15 \mathrm{~mL})$ and methyl $\mathrm{N}, \mathrm{N}, \mathrm{N}^{\prime}, \mathrm{N}^{\prime}$-tetraisopropyl phosphordiamidite $(0.864 \mathrm{~g}, 3.30 \mathrm{mM})$, and allowing $2-3 \mathrm{~h}$ for reaction. TLC in solvents A and D was used to determine reaction completion. The reaction mixture was quenched with saturated aqueous sodium bicarbonate and extracted 3 times with $75 \mathrm{~mL}$ dichloromethane. The combined organic extracts were dried over $\mathrm{Na}_{2} \mathrm{SO}_{4}$ and evaporated. For derivatives of adenosine, cytidine and uridine, the mixture was purified by column chromatography with elution by a gradient from 15 to $50 \%$ dichloromethane in hexanes containing $1 \%$ triethylamine. For the guanosine derivative, the gradient was 0 to $50 \%$ ethyl acetate in dichloromethane containing $1 \%$ triethylamine. Fractions containing pure phosphoramidite were collected and evaporated, coevaporated twice with benzene, then lyophylyzed from benzene. Isolated yields were $65-75 \% .{ }^{31} \mathrm{P}$ NMR spectra had the following resonances (in ppm): (A) 151.81 and 151.68; (C) 151.45 and 150.44; (G) 152.31 and 151.32; (U) 151.68 and 151.60 for 2'-O-methylphosphoramidites. These resonance positions are similar to those reported for the corresponding $2^{\prime}-\mathrm{O}-$ (2-cyanoethyl)phosphoramidites (23).

* To whom correspondence should be addressed 
Oligoribonucleotides longer than hexamers were synthesized manually on Fractosil 500 polymer support with the phosphoramidites described above. The method is analogous to one previously described (17), except methylphosphoramidites were used because they react about $50 \%$ faster than 2-cyanoethylphosphoramidites. Prior to each condensation, dimethoxytrityl was removed with $2 \%$ dichloroacetic acid in dichloromethane (2 additions for $1 \mathrm{~min}$ each). Typical condensation yields were $92 \%$ per step based on release of dimethoxytrityl cation. Hexamers were synthesized with phosphoramidites blocked at the 3'-O with tetrahydropyranyl and deprotected and purified, as previously described (24).

For oligomers with 3 '-O-silyl protecting groups, cleavage from support and removal of base protecting groups was accomplished by a published procedure $(17,25)$. The tert-butyldimethylsilyl was removed by treating with $1 \mathrm{M}$ triethylammonium fluoride in pyridine (50 equivalents for each silyl group) at $50^{\circ} \mathrm{C}$ for $48 \mathrm{~h}$. For $1 \mu$ mole synthesis, the mixture was then dried down and coevaporated twice with $0.5 \mathrm{~mL}$ water. The residue was dissolved in $2 \mathrm{~mL}$ of water and extracted 3 times with $5 \mathrm{~mL}$ of diethyl ether. The oligoribonucleotide in the aqueous layer was partially purified with a Sep-pak C-18 cartridge. Final purification was by HPLC or TLC, as described below.

For purification by HPLC, the aqueous solution was adjusted to $\mathrm{pH}$ 6.5-7, concentrated by drying down, and purified on a Hamilton PRP-1 semipreparative column $(26,27)$. The dimethoxytrityl group was removed by incubation in $80 \%$ acetic acid for $30 \mathrm{~min}$ at room temperature. The oligomer was then desalted and further purified on a Sep-pak C-18 cartridge or a Sephadex G-10 column. Purities were checked by HPLC on a C-8 analytical column, by polyacryamide gel electrophoresis with detection by UV shadowing, and by TLC on a silica gel plate developed with solvent $C$. Purities were greater than $95 \%$. Profiles of $(\mathrm{AG})_{5}$ on the PRP-1 and C-8 columns are shown in Figure 1.

For purification by TLC, the dimethoxytrityl group was first removed by incubation in $80 \%$ acetic acid for $30 \mathrm{~min}$. The oligomer was then purified on a $0.5 \mathrm{~mm}$ silica gel plate developed with solvent $\mathrm{C}$. The slowest mobile spot was scratched out, eluted with water, concentrated, and passed over a Sephadex G-10 column. Purities were determined as described above and were greater than $95 \%$.
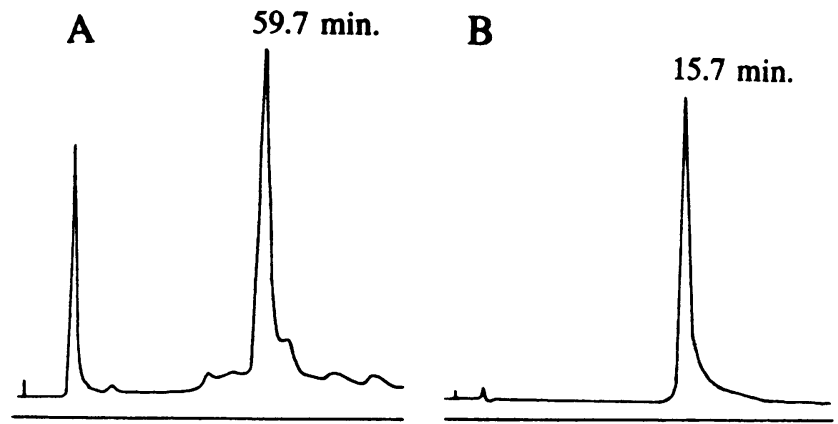

Figure 1. High performance liquid chromatography analysis of $\left(2^{\prime}-5^{\prime}\right)(\mathrm{AG})_{5}$. A) PRP-1 reverse phase column $(0.70 \times 30.5 \mathrm{~cm})$, buffer A: $10 \mathrm{mM}$ aqueous ammonium acetate, buffer $B: 10 \mathrm{mM}$ aqueous ammonium acetate/acetonitrile $(1: 1$ $\mathrm{v} / \mathrm{v}$ ), flow rate: $2 \mathrm{~mL} / \mathrm{min}$, gradient: $30-80 \% \mathrm{~B}$ in $25 \mathrm{~min}$. B) C-8 reverse phase column $(0.46 \times 15 \mathrm{~cm})$, buffer $A: 10 \mathrm{mM}$ aqueous sodium phosphate $\mathrm{pH}$ 7.0 , buffer $\mathrm{B}$ : $10 \mathrm{mM}$ aqueous sodium phosphate $\mathrm{pH} 7.0 /$ methanol $(1: 1 \mathrm{v} / \mathrm{v})$, flow rate: $1 \mathrm{~mL} / \mathrm{min}$, gradient: $0-30 \% \mathrm{~B}$ in $15 \mathrm{~min}$.

\section{Melting Studies}

The buffer for the melting studies was $1.0 \mathrm{M} \mathrm{NaCl}, 10 \mathrm{mM}$ sodium phosphate, $0.5 \mathrm{mM} \mathrm{Na} \mathrm{NDT}_{2}$ A, $\mathrm{pH}$ 7.0. Oligoribonucleotide concentrations $\left(\mathrm{C}_{\mathrm{T}}\right)$ are strand concentrations calculated from the high temperature absorbance at $280 \mathrm{~nm}$. Extinction coefficients were assumed to be the same as for $3^{\prime}-5^{\prime}$ oligomers and were calculated from a nearest neighbor model as described previously (28). These extinction coefficients in units of $10^{4} \mathrm{M}^{-1} \mathrm{~cm}^{-1}$ are as follows : $(\mathrm{AG})_{5}, 5.20$; (CU) $)_{5}, 4.06$; CGGCGCCG, 4.23; GCGCGC, 2.91; UGCGCA, 2.36; GGCGCC, 3.24; GCCGGC, 3.24. Absorbance versus temperature profiles were measured at $280 \mathrm{~nm}$ with a heating rate of $1.0^{\circ} \mathrm{C} \mathrm{m^{-1 }}$ on a Gilford 250 spectrophotometer and analyzed as described previously (30). The extinction coefficients of $2^{\prime}-5^{\prime}$ and $3^{\prime}-5^{\prime}$ single strands may be slightly different. Therefore the dependence of thermodynamic parameters on extinction

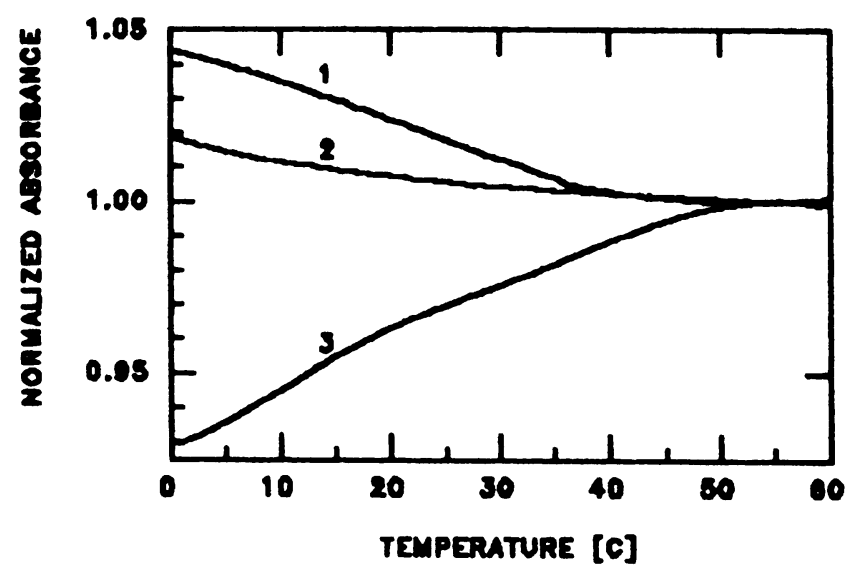

Figure 2. Normalized absorbance at $280 \mathrm{~nm}$ vs temperature for $\left(2^{\prime}-5^{\prime}\right)(\mathrm{CU})_{5}$ (1), $\left(2^{\prime}-5^{\prime}\right)(\mathrm{AG})_{5}(2)$, and a $1: 1$ mixture of $\left(2^{\prime}-5^{\prime}\right)(\mathrm{CU})_{5}$ and $\left(2^{\prime}-5^{\prime}\right)(\mathrm{AG})_{5}$ (3). Absorbances were normalized at $60^{\circ} \mathrm{C}$. Total oligomer strand concentrations were $3.89 \cdot 10^{-4} \mathrm{M}, 3.87 \cdot 10^{-4} \mathrm{M}$, and $4.06 \cdot 10^{-4} \mathrm{M}$ for 1,2 , and 3 , respectively. Solutions are $1 \mathrm{M} \mathrm{NaCl} / 10 \mathrm{mM}$ sodium phosphate $/ 0.5 \mathrm{mM} \mathrm{Na}_{2}$ EDTA, pH 7.0

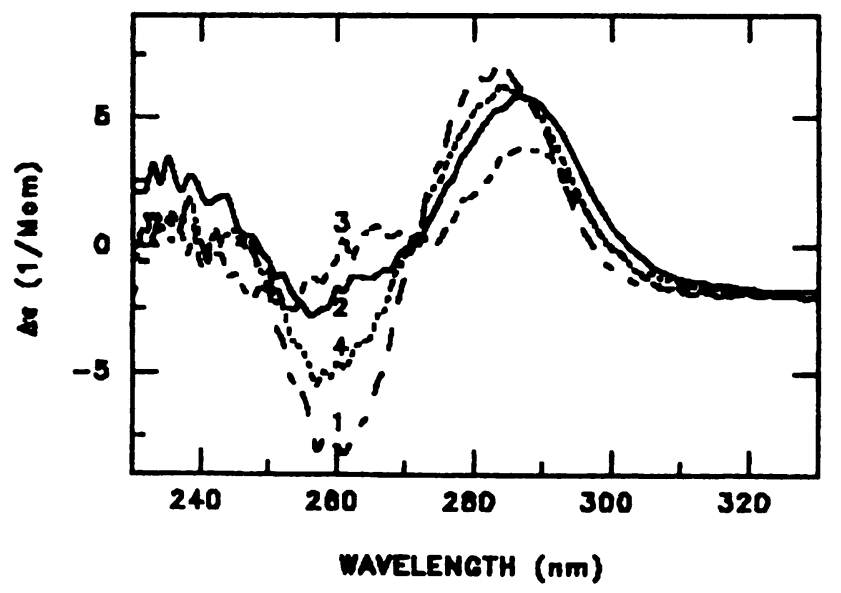

Figure 3. $\mathrm{CD}$ spectra at $0^{\circ} \mathrm{C}$ for $3.34 \cdot 10^{-5} \mathrm{M}\left(2^{\prime}-5^{\prime}\right)(\mathrm{CU})_{5}(1), 3.48 \cdot 10^{-5}$ $\mathrm{M}\left(2^{\prime}-5^{\prime}\right)(\mathrm{AG})_{5}(2)$ and a mixture of $2.1 \cdot 10^{-5} \mathrm{M}\left(2^{\prime}-5^{\prime}\right)(\mathrm{AG})_{5}$ and $2.1 \cdot 10^{-5}$ $M\left(2^{\prime}-5^{\prime}\right)(C)_{5}(3)$. Spectrum $(4)$ is the average of the spectra for $\left(2^{\prime}-5^{\prime}\right)$ $(\mathrm{CU})_{5}$ and $\left(2^{\prime}-5^{\prime}\right)(\mathrm{AG})_{5}$. Solutions are $1 \mathrm{M} \mathrm{NaCl} / 10 \mathrm{mM}$ sodium phosphate/0.5 $\mathrm{mM} \mathrm{Na} \mathrm{N}_{2}$ EDTA, pH 7.0. 
coefficient was tested. For three sequences, including $2^{\prime}-5^{\prime}$ linked CGGCGCCG, the extinction coefficient was changed by $30 \%$. The $\Delta \mathrm{H}^{\circ}$ and $\Delta \mathrm{S}^{\circ} \mathrm{s}$ from both fits and $\log \mathrm{C}_{\mathrm{T}}$ plots changed by less than $1 \%$ and the $\Delta \mathrm{G}_{7}$ changed by less than $4 \%$.

\section{Spectroscopy}

CD spectra were measured for oligomers in melting buffer with a Jasco J-40 spectropolarimeter. The measured CD was converted to $\Delta \epsilon(31)$.

'H NMR spectra were recorded with a Varian VXR-500S spectrometer for oligomers in $90 \% \mathrm{H}_{2} \mathrm{O} / 10 \% \mathrm{D}_{2} \mathrm{O}$ with $0.1 \mathrm{M}$ $\mathrm{NaCl}, 10 \mathrm{mM}$ sodium phosphate, $0.5 \mathrm{mM} \mathrm{Na} \mathrm{EDDT}_{2}$, pH 7.0.

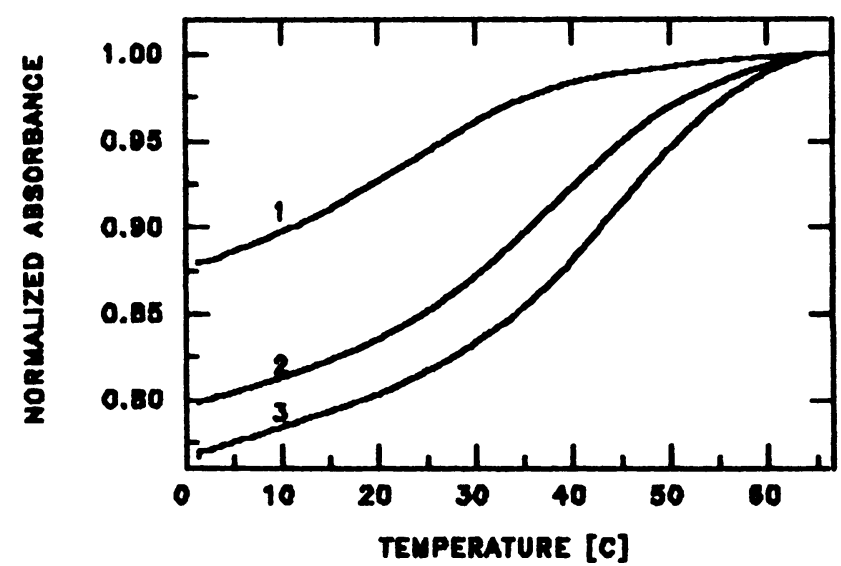

Figure 4. Normalized absorbance at $280 \mathrm{~nm}$ vs temperature for $\left(2^{\prime}-5^{\prime}\right)$ GCGCGC (1), $\left(2^{\prime}-5^{\prime}\right)$ GGCGCC (2) and $\left(2^{\prime}-5^{\prime}\right)$ CGGCGCCG (3). Absorbances were normalized at $65^{\circ} \mathrm{C}$. Oligomer strand concentrations were $1.22 \cdot 10^{-4} \mathrm{M}$, $2.84 \cdot 10^{-4} \mathrm{M}$ and $1.06 \cdot 10^{-4}$ for 1,2 and 3 , respectively. Solutions are $1 \mathrm{M}$ $\mathrm{NaCl} / 10 \mathrm{mM}$ sodium phosphate/0.5 mM Na 2 EDTA, $\mathrm{pH} 7.0$.
${ }^{31} \mathrm{P}$ NMR spectra were measured with a Bruker AMX $400 \mathrm{MHz}$ for phosphoramidites in anhydrous acetonitrile. All peaks are referenced to external $\mathrm{H}_{3} \mathrm{PO}_{4}$ in acetonitrile.

\section{RESULTS}

UV melting curves and CD spectra of $2^{\prime}-5^{\prime}$ linked $(\mathrm{CU})_{5}$ and $(\mathrm{AG})_{5}$ were measured to determine if complementary $2^{\prime}-5^{\prime}$ oligoribonucleotides can associate. Figure 2 shows absorbance at $280 \mathrm{~nm}$ vs temperature for each individual strand and for a $1: 1$ mixture of $(\mathrm{CU})_{5}$ and $(\mathrm{AG})_{5}$. The absorbances of the individual strands decrease with temperature. Some, but not all of this decrease can be attributed to volume expansion, since water expands almost $2 \%$ between and 0 and $60^{\circ} \mathrm{C}$. The additional decrease probably reflects unusual interactions between bases in $2^{\prime}-5^{\prime}$ linked single strands, since absorbances of $3^{\prime}-5^{\prime}$ linked single strands increase with temperature due to loss of base stacking interactions. The absorbance of the mixture, however, increases with temperature. Two transitions are apparent in the mixture, especially at high concentrations of oligomer. Evidently, $(\mathrm{CU})_{5}$ and $(\mathrm{AG})_{5}$ associate. Figure 3 shows $\mathrm{CD}$ spectra for $(\mathrm{CU})_{5},(\mathrm{AG})_{5}$, and a $1: 1$ mixture of the two at $0^{\circ} \mathrm{C}$. The spectrum of the mixture differs significantly from the average of the spectra of $(\mathrm{CU})_{5}$ and $(\mathrm{AG})_{5}$. This also indicates association of the strands.

To check the generality of association of $2^{\prime}-5^{\prime}$ oligomers, melting curves were measured for several self-complementary sequences. As shown in Figure 4 and Table I, all the sequences exhibit melting transitions. The melting temperatures of these transitions are all dependent on oligomer concentration, indicating the transitions involve 2 or more strands. To provide an estimate of the thermodynamic parameters for $2^{\prime}-5^{\prime}$ GCGCGC, GCCGGC, GGCGCC, and UGCGCA associations, melting curves at 2 or more concentrations were fit to a two-state model for dimer formation (30). The averages of the fitted parameters

Table I. Comparision of thermodynamic parameters for duplex formation by $\left(2^{\prime}-5^{\prime}\right)$ and $\left(3^{\prime}-5^{\prime}\right)$ oligoribonucleotides.

\begin{tabular}{|c|c|c|c|c|c|c|c|c|c|c|c|c|}
\hline \multirow[b]{2}{*}{ Sequences } & \multicolumn{4}{|c|}{$\left(2^{\prime}-5^{\prime}\right)$ oligomers ${ }^{2}$} & \multicolumn{4}{|c|}{$\left(3^{\prime}-5^{\prime}\right)$ oligomers $\mathrm{s}^{\mathrm{b}}$} & \multicolumn{4}{|c|}{$\left(3^{\prime}-5^{\prime}\right)-\left(2^{\prime}-5^{\prime}\right)$ data } \\
\hline & $\begin{array}{c}-\Delta \mathrm{H}^{\circ} \\
\mathrm{kcal} / \mathrm{mol}\end{array}$ & $\begin{array}{c}-\Delta S^{\circ} \\
e u\end{array}$ & $\begin{array}{c}-\Delta \mathrm{G}_{37}^{\circ} \\
\mathrm{kcal} / \mathrm{mol}\end{array}$ & $\begin{array}{l}\mathrm{T}_{\mathrm{m}} \\
{ }^{\circ} \mathrm{C}\end{array}$ & $\begin{array}{c}-\Delta \mathrm{H}^{\circ} \\
\mathrm{kcal} / \mathrm{mol}\end{array}$ & $\begin{array}{r}-\Delta S^{\circ} \\
\text { eu } 1\end{array}$ & $\begin{array}{l}-\Delta \mathrm{G}_{37}^{\circ} \\
\mathrm{kcal} / \mathrm{mol}\end{array}$ & $\begin{array}{l}\mathrm{T}_{\mathrm{m}} \\
{ }^{\circ} \mathrm{C}\end{array}$ & $\begin{array}{c}-\Delta \Delta \mathrm{H}^{\circ} \\
\mathrm{kcal} / \mathrm{mol}\end{array}$ & $\begin{array}{c}-\Delta \Delta S^{\circ} \\
\mathrm{eu}\end{array}$ & $\begin{array}{l}-\Delta \Delta \mathrm{G}^{\circ}{ }_{37} \\
\mathrm{kcal} / \mathrm{mol}\end{array}$ & $\begin{array}{l}\Delta \mathrm{T}_{\mathrm{m}} \\
{ }^{\circ} \mathrm{C}\end{array}$ \\
\hline$(\mathrm{AG})_{s} \cdot(\mathrm{CU})_{s}$ & & & & $12^{\mathrm{c}} ; 35^{\mathrm{c}}$ & $91.2^{\mathrm{d}}$ & $250.2^{\mathrm{d}}$ & $13.9^{\mathrm{d}}$ & $66.5^{d}$ & & & & \\
\hline CGGCGCCG & $\begin{array}{c}43.5 \\
(44.3)\end{array}$ & $\begin{array}{c}118.0 \\
(121.2)\end{array}$ & $\begin{array}{l}6.9 \\
(6.8)\end{array}$ & $\begin{array}{r}46.0 \\
(45.3)\end{array}$ & $76.8^{d}$ & $199.6^{\mathrm{d}}$ & $14.8^{\mathrm{d}}$ & $79.3^{\mathrm{d}}$ & 33.3 & 81.6 & 7.9 & 33.3 \\
\hline GGCGCC & 29.7 & 79.4 & 5.1 & 30.9 & 67.8 & 182.0 & 11.3 & 65.2 & 38.1 & 102.6 & 6.2 & 34.3 \\
\hline GCGCGC & $\begin{array}{c}28.3 \\
(22.2)\end{array}$ & $\begin{array}{c}76.6 \\
(56.2)\end{array}$ & $\begin{array}{l}4.5 \\
(4.8)\end{array}$ & $\begin{array}{l}25.0 \\
(24.4)\end{array}$ & 66.0 & 178.5 & 10.6 & 62.1 & 37.7 & 101.9 & 6.1 & 37.1 \\
\hline GCCGGC & 31.7 & 88.4 & 4.3 & 23.8 & 62.7 & 166.0 & 11.2 & 67.2 & 31.0 & 77.6 & 6.9 & 43.4 \\
\hline UGCGCA & 28.7 & 81.1 & 3.5 & 15.2 & 51.5 & 139.7 & 8.2 & 53.1 & 22.8 & 58.6 & 4.7 & 37.9 \\
\hline
\end{tabular}

a-Values not in parentheses are averages of fits of 2 or more melting curves. Values in parentheses are from $T_{m}{ }^{-1} v s \log C_{T}$ plots. b-see reference 39 . c-value estimated from melting curve. d-value calculated (see reference 39 ). 
are listed in Table I. For GCGCGC and CGGCGCCG, thermodynamic parameters were also obtained from a plot of inverse melting temperature, $T_{M}{ }^{-1}$, vs $\log C_{T}$ according to (29):

$$
\frac{1}{T_{M}}=\frac{2.3 R}{\Delta H^{\circ}} \log C_{T}+\frac{\Delta S^{\circ}}{\Delta H^{\circ}}
$$

The $\log \mathrm{C}_{\mathrm{T}}$ plot for CGGCGCCG is shown in Figure 5, and the parameters are listed in Table $\mathrm{I}$. There is excellent agreement between the thermodynamic parameters obtained from eq 1 and from averaging the fits of individual melting curves. This suggests CGGCGCCG associates in a two-state manner to the dimer, (CGGCGCCG) $)_{2}$ (32).

The melting behavior of the $2^{\prime}-5^{\prime}$ oligomers can be compared with that measured or predicted for the same sequences with $3^{\prime}-5^{\prime}$ linkages. Thermodynamic parameters for duplex formation by the $3^{\prime}-5^{\prime}$ sequences are also listed in Table I. Evidently, melting temperatures for $2^{\prime}-5^{\prime}$ sequences are $30-40^{\circ} \mathrm{C}$ lower than for $3^{\prime}-5^{\prime}$ sequences due to roughly a factor of 2 less favorable apparent $\Delta \mathrm{H}^{\circ}$.

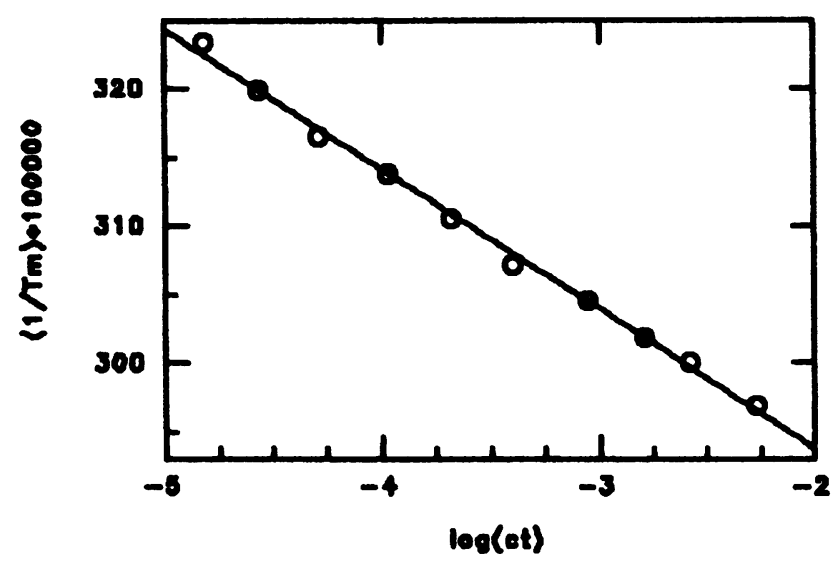

Figure 5. Reciprocal melting temperature vs $\log$ (strand concentration) for $\left(2^{\prime}-5^{\prime}\right)$ CGGCGCCG. Solutions are $1 \mathrm{M} \mathrm{NaCl} / 10 \mathrm{mM}$ sodium phosphate/0.5 mM Na EDTA, pH 7.0.

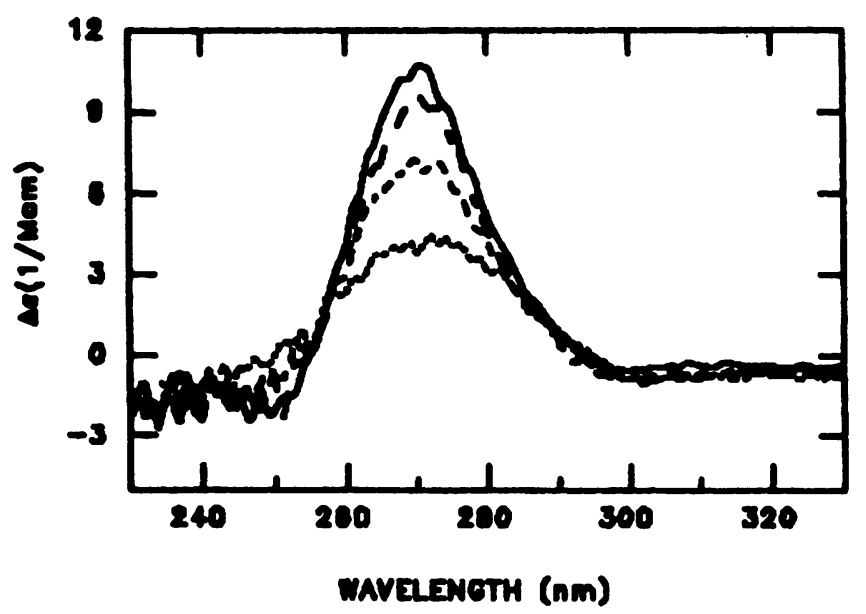

Figure 6. Temperature dependent $\mathrm{CD}$ spectra of $1.10 \cdot 10^{-4} \mathrm{M}\left(2^{\prime}-5^{\prime}\right)$ CGGCGCCG at $0^{\circ} \mathrm{C}(-), 20^{\circ} \mathrm{C}(--), 40^{\circ} \mathrm{C}(--)$ and $60^{\circ} \mathrm{C}(\cdots)$. Solutions are $1 \mathrm{M} \mathrm{NaCl} / 10 \mathrm{mM}$ sodium phosphate/0.5 mM Na${ }_{2}$ EDTA, pH 7.0.
To provide further insight into associations of $2^{\prime}-5^{\prime}$ oligomers, $\mathrm{CD}$ and ' $\mathrm{H}$ NMR spectra were measured for CGGCGCCG. As shown in Figure 6, the CD spectrum at low temperatures is similar to that expected for a right handed double helix with $3^{\prime}-5^{\prime}$ linkages (33). At high temperature, the ellipticity is reduced considerably, as expected for a transition to a random coil (34). As shown in Figure 7, the NMR spectrum at $10^{\circ} \mathrm{C}$ exhibits 4 major resonances from $11.8-13.0 \mathrm{ppm}$. This is the region where imino protons in GC pairs typically resonate $(35,36)$. Three of the resonances are sharp and one is broad. Thus the complex has 4 imino protons exchanging slowly with water, with one of them exchanging faster than the others. This is the pattern expected for the self-complementary duplex, (CGGCGCCG) ${ }_{2}$, since terminal GC base pairs generally exchange with water faster than internal base pairs. Three minor resonances are also observed in the spectrum suggesting some slow chemical exchange for the complex.

The spatial proximity of the imino protons was probed by 1-D NOE experiments. As shown in Figure 7, irradiation of the resonances at 12.6 or $12.9 \mathrm{ppm}$ gives NOES to the resonance at $13.0 \mathrm{ppm}$. Irradiation at $13.0 \mathrm{ppm}$ gives an NOE at $12.9 \mathrm{ppm}$. This is consistent with a duplex of antiparallel strands with the resonance assignments given in Figure 7.

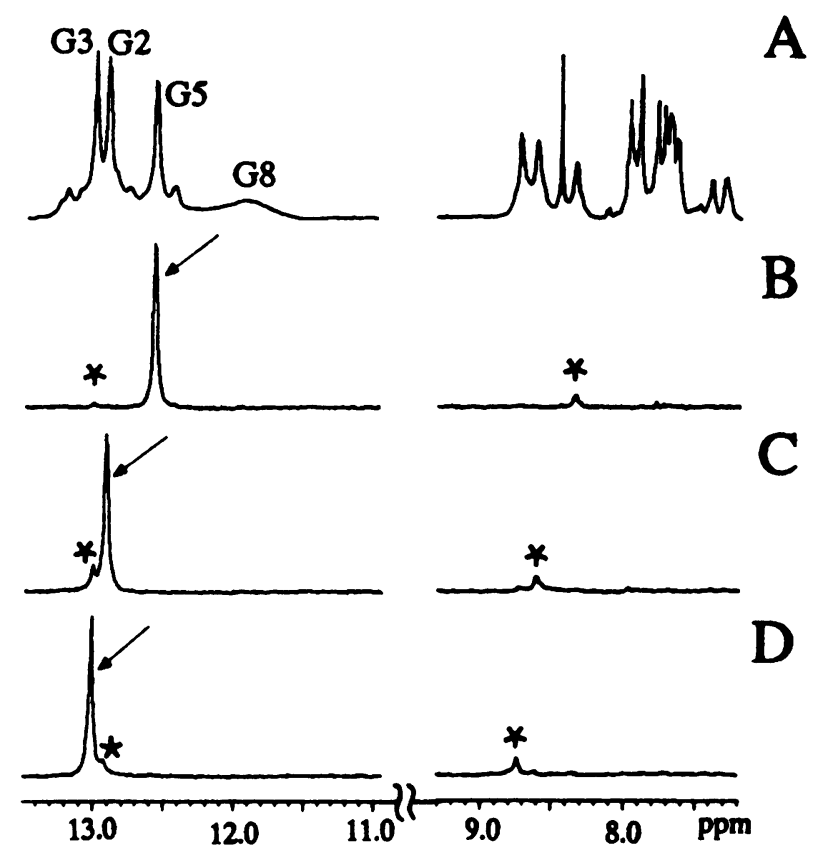

Figure 7. (A) 500-MHZ proton NMR spectrum of $1.4 \mathrm{mM}\left(2^{\prime}-5^{\prime}\right)$ CGGCGCCG at $10^{\circ} \mathrm{C}$ in $0.1 \mathrm{M} \mathrm{NaCl}, 10 \mathrm{mM}$ sodium phosphate, and $0.5 \mathrm{mM} \mathrm{Na}$, EDTA in $90 \% \mathrm{H}_{2} \mathrm{O}, \mathrm{pH}$ 7.0. Chemical shifts are referenced to internal 3-(trimethylsilyl) tetradeutero sodium propionate (TSP). Line broadening of $2 \mathrm{~Hz}$ was applied before Fourier transformation. Difference spectra following 1-s saturation of $(B)$ the resonance at $12.59 \mathrm{ppm},(\mathrm{C})$ the resonance at $12.93 \mathrm{ppm}$, and (D) the resonance at $13.02 \mathrm{ppm}$. The decoupler power levels are adjusted to saturate $80 \%$ of the resonance desired. For (C) and (D), the saturation was applied at 12.92 and 13.03 $\mathrm{ppm}$, respectively, in order to avoid spillover artefacts. The saturated resonance is designated by an arrow while the observed NOE's are designated by asterisks. Assignments are shown above spectrum A. For NOE difference spectra, experiments with irradiation on and off resonance were collected in blocks of 16 scans and interleaved to correct for long-term instrumental drift. The 1:3:3:1 pulse sequence (40) was used as the read pulse. $12 \mathrm{kHz}$ spectral width was employed with the carrier frequency set at the water resonance and the delays set to maximize signal to noise at $-12 \mathrm{ppm}$. 
As shown in Figure 7, irradiation of the imino proton resonances also gives NOEs to resonances between 8.3 and 8.8 $\mathrm{ppm}$. This is the region where protons from hydrogen bonded cytosine amino groups typically resonate (35). Observation of these NOEs suggests hydrogen bonding of these amino groups, since cytosine amino groups that are not hydrogen bonded typically resonate between 6 and 7 ppm (36).

\section{DISCUSSION}

The ability of $2^{\prime}-5^{\prime}$ linked oligoribonucleotides to form ordered structures is largely unexplored. Theoretical studies have led to conflicting opinions about the possibilities for forming double helixes $(7,8)$. The only experimentally observed double helix containing $2^{\prime}-5^{\prime}$ oligomers is the mismatched CA helix observed by $\mathrm{X}$-ray diffraction (16). We have modified the methods commonly used for synthesis of $3^{\prime}-5^{\prime}$ linked oligomers (17) to give $2^{\prime}-5^{\prime}$ linkages. The results presented above indicate several of these $2^{\prime}-5^{\prime}$ oligomers can associate. Of the sequences studied, complexes were formed by all that had Watson-Crick complementarity for antiparallel strands. The individual non-selfcomplementary strands, $(\mathrm{CU})_{5}$ and $(\mathrm{AG})_{5}$, did not separately form complexes. They did associate, however, when mixed together. The thermodynamic and NMR studies of CGGCGCCG are consistent with formation of a duplex involving hydrogen bonding of both imino and amino protons. Thus the data suggest $2^{\prime}-5^{\prime}$ oligomers can form antiparallel duplexes involving Watson-Crick hydrogen bonding. Such hydrogen bonding is known to provide a favorable free energy for association $(37,38)$.

The imino proton chemical shifts and CD spectra for CGGCGCCG at low temperature are similar to those observed for right handed $3^{\prime}-5^{\prime}$ double helixes $(33,35,36)$. Both spectroscopic properties are dependent on stacking patterns. The results suggest stacking interactions may also stabilize the duplex.

While the CGGCGCCG duplex appears to be stabilized by the same forces as $3^{\prime}-5^{\prime}$ duplexes, its overall stability is much lower. At $10^{-4} \mathrm{M}$, the melting temperature for the $2^{\prime}-5^{\prime}$ duplex is $46^{\circ} \mathrm{C}$. This is less than the observed $\mathrm{T}_{M}$ of $65^{\circ} \mathrm{C}$ for the $3^{\prime}-5^{\prime}$ linked duplex, GGCGCC (39). Nearest neighbor parameters can be used to extrapolate the results for $3^{\prime}-5^{\prime}$ GGCGCC to $3^{\prime}-5^{\prime}$ CGGCGCCG (39). The predicted $\mathrm{T}_{\mathrm{M}}$ is $79^{\circ} \mathrm{C}$. The $\Delta \mathrm{G}^{\circ}$ for formation of $2^{\prime}-5^{\prime}$ (CGGCGCCG) ${ }_{2}$ at $37^{\circ} \mathrm{C}$ is $-6.8 \mathrm{kcal} / \mathrm{mol}$, whereas that predicted for the $3^{\prime}-5^{\prime}$ duplex is $-14.8 \mathrm{kcal} / \mathrm{mol}$. Thus the $2^{\prime}-5^{\prime}$ duplex is $1 \mathrm{kcal} / \mathrm{mol}$ less stable per base pair. Similar differences are observed for the other sequences listed in Table I. In contrast to the free energy differences, the entropy changes for association of $2^{\prime}-5$ ' oligomers are more favorable than for $3^{\prime}-5^{\prime}$ oligomers. Theoretical studies indicate that single stranded $2^{\prime}-5^{\prime}$ oligomers have fewer low energy conformations than $3^{\prime}-5^{\prime}$ oligomers $(7,8)$. Thus there should be less of an entropy penalty associated with forming ordered structures between $2^{\prime}-5^{\prime}$ oligomers. This is consistent with the results in Table I. Evidently, the lower stability of $2^{\prime}-5^{\prime}$ complexes is the result of a less favorable enthalpy change for association. This suggests $2^{\prime}-5^{\prime}$ complexes have weaker bonding than $3^{\prime}-5^{\prime}$ complexes.

It has been suggested that $3^{\prime}-5^{\prime}$ linkages were selected during evolution because they hydrolyze slower than $2^{\prime}-5^{\prime}$ linkages (5). The results above suggest another contributing factor: duplex structures formed by $2^{\prime}-5^{\prime}$ oligomers are less stable than those formed by $3^{\prime}-5^{\prime}$ oligomers. Thus formation of a particular structure or generation of a code would require more nucleotides per element. This could provide a negative selective pressure.

\section{ACKNOWLEDGEMENTS}

This work was supported by National Institutes of Health Grant GM22939. We thank Dr. John SantaLucia, Jr. for preliminary NMR spectra, and Drs. Carl Longfellow and Adam Peritz for help with the thermodynamic measurements.

\section{REFERENCES}

1. Cech, T. R. (1990) Annu. Rev. Biochem., 59, 543-568.

2. Zamecnik, P. C. and Stephenson, M. L. (1978) Proc. Natl. Acad. Sci. U.S.A., 75, 280-284.

3. Uhlmann, E. and Peyman, A. (1990) Chemical Reviews, 90, 543-584.

4. Orgel, L. E. and Lohrmann, R. (1974) Acc. Chem. Res., 7, 368-377.

5. Usher, D. A. and McHale, A. H. (1976) Proc. Natl. Acad. Sci. U.S.A., 73, $1149-1153$.

6. Dhingra, M. M. and Sarma, R. H. (1978) Nature, 272, 798-801

7. Anukanth, A. and Ponnuswamy, P. K. (1986) Biopolymers, 25, 729-752.

8. Srinivasan, A. R. and Olson, W. K. (1986) Nucleic Acids Res., 14, $5461-5479$.

9. Brahms, T., Maurizot, T. C. and Michelson, A. M. (1967) J. Mol. Biol., 25, $481-495$.

10. Adler, A. J., Grossman, L. and Fasman, G. D. (1968) Biochemistry, 7 3836-3843.

11. Warshaw, M. M. and Cantor, C. R. (1970) Biopolymers, 9, 1974-1103.

12. Kondo, N. S., Holmes, H. M., Stempel, L. M. and Ts'o, P. O. P. (1970) Biochemistry, 9, 3479-3498.

13. Doornbos, J., Den Hartog, J. A. J., van Boom, J. A. and Altona, C. (1981) Eur. J. Biochem., 116, 403-412.

14. Parthasarathy, R., Malik, M. and Fridey, S. M. (1982) Proc. Natl. Acad. Sci. U.S.A., 79, 7292-7296.

15. Doornbos, J., Charubala, R., Pfleiderer, W. and Altona, C. (1983) Nucleic Acids Res., 11, 4569-4582.

16. Krishnan, R., Seshadri, T. P. and Viswamitra, M. A. (1991) Nucleic Acids Res., 19, 379-384.

17. Ogilvie, K. K., Usman, N., Nicognosian, K. and Cedegren, R. J. (1989) Proc. Natl. Acad. Sci. U.S.A., 85, 5764-5768.

18. Barone, A. D., Tang, J-Y. and Caruthers, M. H. (1984) Nucleic Acids Res. 12, $4051-4061$.

19. Sung, L. W. and Narang, S. A. (1982) Can. J. Chem., 60, 111-120.

20. Chaix, C., Molko, D. and Teoule, R. (1989) Tetrahedron Let., 30, $71-74$

21. Kierzek, R. (1985) Nucleosides and Nucleotides, 4, 641-649.

22. Markiewicz, W. T., Biala, E. and Kierzek, R. (1984) Bull. Pol. Acad. Sci. Chem., 32, 433-451.

23. Scaringe, S. A., Francklyn, C. and Usman, N. (1990) Nucleic Acids Res., 18, 5433-5441.

24. Kierzek, R., Markiewicz, W. T. and Imiolczyk, B. (1987) Biophosphates and Their Analogues-Synthesis, Structure, Metabolism and Activity, Bruzik, K. S. and Stec. W. J. (eds), Elsevier, Amsterdam.

25. Stawinski, J., Stroemberg, R., Thelin, M., Westman, E. (1988) Nucleic Acids Res., 16, 9285-9298.

26. Ikuta, S., Chattopadhyaya, R. and Dickerson, R. E. (1984) Anal. Chem., 56, $2253-2856$.

27. Longfellow, C. E., Kierzek, R. and Turner, D. H. (1990) Biochemistry, 29, 278-285.

28. Richards, E. G. (1975) in Handbook of Biochemistry and Molecular Biology: Nucleic Acids (Fasmak, G. D. Ed.) 3rd Vol. I, p. 597, CRC Press Cleveland, $\mathrm{OH}$.

29. Borer, P. N., Dengler, B., Tinoco, I., Jr. and Uhlenbeck, O. C. (1974) J. Mol. Biol., 86, 843-853.

30. Petersheim, M. and Turner, D. H. (1983) Biochemistry, 22, 256-263.

31. Cantor, C. R. and Schimmel, P. R. (1980) Biophysical Chemistry Part II: Techniques for the Study of Biological Structure and Function, Chapter 8, Freeman, W. H., San Francisco, CA.

32. SantaLucia, J., Jr., Kierzek, R. and Turner, D. H. (1990) Biochemistry, 29, 8813-8819.

33. Tunis-Schneider, M. J. B. and Maestre, M. F. (1970) J. Mol. Biol., 52, $521-541$.

34. Van Holde, K. E., Brahms, J. and Michelson, A. M. (1965) J. Mol. Biol. 12, 726-739. 
1690 Nucleic Acids Research, Vol. 20, No. 7

35. Wuthrich, K. (1986) NMR of Proteins and Nucleic Acids. J. Wiley and Sons, New York, p. 34, 249.

36. Patel, D. J. (1976) Biopolymers, 15, 533-558, ibid (1977), 16, 1635-1656.

37. Turner, D. H., Sugimoto, N., Kierzek, R. and Dreiker, S. D. (1987) $J$. Am. Chem. Soc., 104, 3783-3785.

38. Freier, S. M., Sugimoto, N., Sinclair, A., Alkema, D., Neilson, T., Kierzek, R., Caruthers, M. H. and Turner, D. H. (1986) Biochemistry, 25, 3214-3219.

39. Freier, S. M., Kierzek, R., Jaeger, J. A., Sugimoto, N., Caruthers, M. H., Neilson, T. and Turner, D. H. (1986) Proc. Natl. Acad. Sci. U.S.A., 83, 9373-9377

40. Hore, P. J. (1983) J. Magn. Reson. 55, 283-300. 